\title{
Planejamento estratégico e gestão pública por resultados no processo de reforma administrativa do estado de Minas Gerais*
}

\author{
Izabela Moreira Corrêa **
}

SUMÁRIO: 1. Introdução; 2. Estado e economia no Brasil dos anos 1990: o marco institucional que viabilizou a reforma administrativa do estado de Minas Gerais; 3. A lógica do planejamento estratégico como foco de atenção da reforma administrativa e da estratégia de governo em Minas Gerais; 4. Considerações finais.

SUMMARY: 1. Introduction; 2. State and the Brazilian economy in the nineties: the institutional landmark that made possible the administrative reform of the state of Minas Gerais, Brazil; 3. The strategic planning logic as the focus of the administrative reform and of the government's strategy on the state of Minas Gerais; 4. Final remarks.

PAlAVRAS-CHAVE: planejamento estratégico; gestão pública por resultados; reforma administrativa.

KEY WORDS: strategic planning; public management by results; administrative reform.

Reformar uma organização já é, administrativamente, uma tarefa árdua. Reformar uma organização como o Estado pode ser ainda mais complicado. Essa tarefa pode tornar-se menos complexa quando o governo é capaz de estabelecer estratégias claras de intervenção no modelo de administração pública e negociação com o Legislativo. Neste artigo desenvolve-se o argumento de que o processo de reforma do Estado em Minas Gerais foi viabilizado pelo desenvolvimento do planejamento estratégico e facilitado

\footnotetext{
* Artigo recebido em set. 2006 e aceito em mar. 2007.

** Analista do Banco Central do Brasil, pesquisadora do Centro de Estudos Legislativos da Faculdade de Filosofia e Ciências Humanas (Fafich) da UFMG. Mestre em ciência política pela Fafich/UFMG, graduada em administração pública pela Escola de Governo da Fundação João Pinheiro. Endereço: SQN 311, Bloco B, ap. 301 - Brasília, DF, Brasil. E-mail: izabela.correa@terra.com.br.
} 
pela política de gestão pública por resultados — acordo de resultados que garantiu o alinhamento estratégico dos órgãos, entidades e servidores às metas do governo. Mostra-se, ainda, como mesmo em um contexto de reforma do Estado, em que há ampliação do papel regulador do Estado e redução de seu papel de provedor, é possível aumentar os graus de accountability e responsiveness, bem como fortalecer a sociedade civil.

Strategic planning and public management by results in the administrative reform process of the state of Minas Gerais, Brazil Organization reform is by itself a tough administrative task. State reform can be even harder. Nevertheless, it can be less difficult if the government is able to establish strategies to remodel the public administration apparatus and to negotiate with the Legislative. This article argues that the state reform in Minas Gerais was enabled by the development of strategic planning and by the implementation of a public management by results policy - result agreement. This article also demonstrates that even when state reform takes place in a context in which the state has a bigger regulatory role and a smaller provider role it is possible to increase accountability and responsiveness and to strengthen civil society.

\section{Introdução}

O sistema econômico mais racional e humanitário é aquele que depende da existência de mercados regulados para a alocação de recursos e da presença do Estado para garantir um bem-estar material básico para todos. (...) Para que as instituições democráticas suscitem adesão e se consolidem, elas precisam ser, em certa medida, justas e, além disso, eficazes.

Przeworski, 1994

Apesar de por muito tempo ter perdurado a idéia de que a redução da intervenção do Estado na economia teria grandes conflitos em um governo democrático, as democracias modernas correm cada vez mais em direção à adesão de Estados reduzidos. Assim, instituições democráticas devem ser capazes de, sobretudo, constituir governos com capacidade de reagir à mudança das relações entre as forças políticas; possuir mecanismos de consulta ou controle dos cidadãos sobre os representantes para a formulação e implementação de políticas públicas; e respeitar as instituições políticas em vigência.

Estruturar o Estado capitalista e aprofundar os mecanismos de democracia vem tomando a atenção de especialistas (Offe, 1984; Przeworski, 1994, 1995; Lijphart, 2003), fazendo com que a economia política alcance visibilidade em todo o mundo. O intento, todavia, de cientistas políticos e economistas 
políticos em estudarem o fenômeno da inter-relação entre democracia e mercado está extremamente relacionado à emergência de um novo modelo de atuação estatal. Desde detectada a obsolescência do modelo burocrático weberiano, na década de 1980, a partir de um diagnóstico da incapacidade do Estado de atendimento dos anseios da administração pública e dos cidadãos, novos modelos surgem na direção de um modelo de Estado gerencial. As mudanças verificadas em diversos países do mundo, apesar de um longo processo de mudanças, permanecem. ${ }^{1}$ Reformas de Estado continuam acontecendo e sua relação com a democracia permanece sendo um desafio para os governos que as promovem.

Este artigo aponta como a modernização administrativa do estado de Minas Gerais vem conseguindo, com sucesso, entrelaçar reforma de Estado e ampliação da democracia, por meio da especialização da função planejamento estratégico no Estado, especialmente com a gestão pública por resultados. Dessa forma este artigo procura explicitar como o governo mineiro conseguiu implementar a lógica de planejamento estratégico público, fortalecendo o entendimento da missão do Estado e a atuação da sociedade civil, aumentando os graus de accountability horizontal e vertical.

A primeira seção deste artigo apresenta o marco regulatório nacional que subsidiou a reforma administrativa no estado de Minas Gerais. Esta, por sua vez, é apresentada na segunda seção, com especial ênfase no planejamento estratégico, na gestão pública por resultados e na participação do Legislativo e cidadãos nos processo de reforma. Considerações finais serão realizadas na última seção.

\section{Estado e economia no Brasil dos anos 1990: o marco institucional que viabilizou a reforma administrativa do estado de Minas Gerais}

A implementação da lógica do planejamento estratégico no estado de Minas Gerais deu-se em um contexto mais amplo, qual seja o da reforma administrativa do estado de Minas Gerais, que, por sua vez, esteve continuamente orientada pela última reforma administrativa do governo federal, levada a cabo a

\footnotetext{
${ }^{1}$ Se em 15 de setembro de 2005 a publicação online da revista The Economist lançava olhos sobre as eleições no Japão com ênfase para as reformas do aparelho de Estado que, de certa forma, estavam orientando as eleições, quatro dias depois chamava a atenção para as eleições na Alemanha e, mais uma vez, atentava para a questão da reforma de Estado.
} 
partir de 1995. O Brasil presenciou, até hoje, quatro grandes reformas administrativas - enquanto a reforma de 1934, de caráter essencialmente centralizador, procurou desenvolver o sistema de mérito no serviço civil federal, culminando com a criação do Dasp na Constituição de 1937, a reforma de 1967 institucionalizou práticas de planejamento estratégico, orçamento, delegação e coordenação, alterando totalmente os princípios de organização da administração pública federal. ${ }^{2}$ A Constituição de 1988 criou condições para uma ampla reforma administrativa, podendo, assim, ser considerada, em partes, uma reforma administrativa (Gaetani, 2005). A reforma que teve início em 1988 apresentaria grandes desdobramentos e rearranjos, seguindo tendências mundiais, sete anos mais tarde. A reforma do aparelho de Estado, promovida a partir de 1995 no governo Fernando Henrique Cardoso, teve como principal função o desenvolvimento de novas visões e metas para o Estado, onde o mercado econômico também passaria a ter condições mais favoráveis para seu desenvolvimento.

A reforma administrativa da década de 1990, levada a cabo pelo Ministério de Administração e Reforma do Estado (Mare), foi justificada no Plano Diretor da Reforma Administrativa do Aparelho do Estado como conseqüência de uma crise do Estado, definida como:

1. uma crise fiscal, caracterizada pela presente perda do crédito por parte do Estado e pela poupança pública que se torna negativa; 2. o esgotamento da estratégia estatizante de intervenção do Estado, a qual se reveste de várias formas: o Estado do bem-estar social nos países desenvolvidos, a estratégia de substituição de importações no terceiro mundo e o estadismo nos países comunistas; e, 3. a superação da forma de administrar o Estado, isto é, a superação da administração pública burocrática.

(Mare, 1995:15) ${ }^{3}$

Assim, a reforma administrativa do governo federal seguiu cinco orientações resultantes das três macroorientações estabelecidas pelo plano diretor:

\footnotetext{
${ }^{2}$ Como herança dessa reforma, ainda estão vigentes no arcabouço institucional brasileiro a Lei no 4.320/64; o Decreto-Lei no 199 , que redefiniu o modus operandi de controle na administração pública federal; e o Decreto-Lei no 200.

${ }^{3}$ Vale, contudo, ressaltar que a intenção da implementação de estratégias gerenciais no Estado não visa a superação total do conceito weberiano de burocracia, mas sim fazer com que os elementos essenciais deste modelo de administração - racionalidade e norma - atendam de forma superior às necessidades da população (Lima Junior, 1998).
} 
จ introduzir no governo alguns dos parâmetros de trabalho próprios do setor privado, como a própria lógica de resultados;

v fortalecer as carreiras estratégicas e gerenciais;

จ encorajar descentralização, delegação e devolução;

จ revisar os princípios hierárquicos do funcionalismo público;

$\checkmark$ reduzir o Estado empreendedor, por meio de privatização, e transferência de funções executivas de interesses sociais - quando não disser respeito às atividades exclusivas do Estado - por meio de instrumentos de contratualização (Gaetani, 2005).

No intuito de definir o planejamento estratégico a partir da visão e da missão do Estado, o Plano Diretor da Reforma do Estado definiu os quatro setores de atuação do Estado: o núcleo estratégico; as atividades exclusivas; os serviços não-exclusivos; e a produção de bens e serviços para o mercado. A partir dessa definição formou-se a orientação de como deveria ser a atuação do Estado em cada um dos setores.

O núcleo estratégico foi definido como o centro de decisão do governo, onde foram formuladas as políticas e as leis que orientaram a execução de todas as demais atividades. Atividades exclusivas foi o nome dado ao setor em que a produção dos serviços deveria, necessariamente, ser realizada pelo Estado, tais como serviços de fiscalização e poder de polícia, entre outros. Nesse sentido o plano diretor previa a criação de agências executivas mais flexíveis, dotadas de maior autonomia de gestão. Os serviços não-exclusivos referiramse a serviços em que, além do Estado, atuariam organizações públicas nãoestatais e a iniciativa privada. Nesse âmbito, o Estado ficaria responsável pelo fomento e controle dos resultados, permitindo que a execução direta desses serviços fosse realizada pelas organizações públicas não-estatais. A produção de bens para o mercado caracterizava-se por atividades voltadas para o mercado, que deveriam ser transferidas para a iniciativa privada, necessitando de forte regulação quando se tratarem de monopólios naturais.

O contrato de gestão apresentou-se como o instrumento de ligação entre o núcleo estratégico - responsável pela formulação e avaliação de políticas - e os setores de execução das políticas públicas. O contrato de gestão deveria conter a estipulação das metas a serem atingidas e os respectivos prazos de execução, bem como previsão expressa dos critérios objetivos de avaliação de desempenho a serem utilizados, mediante indicadores de qualidade e produtividade, a estipulação dos limites e critérios para despesa com remuneração. Celebrado o contrato de gestão e atendidos os demais requisitos previs- 
tos em regulamento, as agências executivas e as organizações sociais garantiam maiores flexibilidade e autonomia gerencial, vantagens que dependiam do fiel cumprimento das metas e resultados estipulados nos contratos.

Em 1999, outro instituto legal foi criado com o intuito de implementar a reforma gerencial: as organizações da sociedade civil de interesse público (Oscips), especificamente voltadas para as atividades não-exclusivas do Estado, assumiram a prestação direta de serviços à população. Nesse caso, decidiuse que as metas e resultados a serem alcançados seriam estabelecidos por meio de um termo de parceria constantemente avaliado e acompanhado pelo poder público.

A reforma administrativa institucionalizada a partir de 1995 no Brasil havia, assim, estabelecido o marco institucional para a promoção de reformas administrativas nos demais entes da Federação. Foi a partir desse ponto que pôde ser considerada uma alteração na administração pública mineira. Só que em Minas Gerais o planejamento estratégico e a gestão pública por resultados tornaram-se aspectos marcantes do processo de implementação da reforma administrativa e da estratégia política.

\section{A lógica do planejamento estratégico como foco de atenção da reforma administrativa e da estratégia de governo em Minas Gerais}

O processo de reforma administrativa do estado de Minas Gerais começou pela definição da visão, da missão e das metas do Estado. Para dar início ao processo de implementação da reforma administrativa, o governo priorizou diversas políticas públicas que deveriam ser geridas sob as estratégias de gestão definidas no "choque de gestão". O "choque de gestão" pode ser definido como o processo de reengenharia pela qual passou o estado de Minas Gerais nos últimos três anos.

Entre as diversas políticas que compunham o choque de gestão, uma característica esteve sempre presente: a estratégia do planejamento estratégico. Nesse sentido, e tomando por base a reforma administrativa levada a cabo no Brasil em 1995, a lógica de intervenção do setor público em Minas Gerais foi revertida para uma lógica de planejamento estratégico da ação estatal baseada em resultados. Para viabilizar o desenvolvimento de um governo que consiga a implementação de políticas públicas como resultado de um processo de planejamento estratégico, foram definidas iniciativas de curto prazo que facilitariam o alcance dos resultados almejados no longo prazo. 
Como iniciativa de curto prazo, o estado de Minas Gerais presenciou um processo de reforma do Estado que, por si, já deu início a um processo de reforma institucional que garantiria que o processo de planejamento perdurasse e tivesse eficácia. Foram instituídos: o colegiado de gestão governamental e as câmaras temáticas; as áreas de planejamento, de gestão e de finanças de cada órgão e entidade foram integradas; a função de gerente executivo de projetos foi implementada; o comitê de governança eletrônica; e, entre outras iniciativas, o modelo de Oscip como estratégia de fortalecimento da sociedade civil na promoção de serviços não-exclusivos do Estado.

Todas essas alternativas de intervenções de curto prazo permitiram que o governo pudesse considerar um contexto de déficit público e, ainda assim, partir para outras priorizações de estratégias políticas. A grande iniciativa para o desenvolvimento da lógica do planejamento estratégico como política de gestão do governo foi a integração entre planejamento e orçamento. Em Minas Gerais o ciclo orçamentário inicia-se com o desenvolvimento do Plano Mineiro de Desenvolvimento Integrado (PMDI), seguido de instrumentos instituídos pela Constituição Federal, quais sejam o Plano Plurianual de Ação Governamental (PPAG), a Lei de Diretrizes Orçamentárias (LDO) e a Lei Orçamentária Anual (LOA).

O PMDI foi definido, na Constituição estadual de Minas Gerais, como um plano plurianual de desenvolvimento a ser apresentado pelo Executivo e discutido com os demais representantes dos cidadãos no estado. Ao contrário do que vinha sendo elaborado em Minas Gerais desde a institucionalização do PMDI, com planos que se estendiam pelo período de quatro anos, em $2004 \mathrm{o}$ Executivo estadual propôs um plano que permitiria aos representantes e aos cidadãos conhecerem todos os componentes da matriz SWOT — forças, fraquezas, oportunidades e ameaças - para o governo do estado e, assim, poder traçar um plano de governo que fosse sustentado em estratégias de gestão que permitiriam o desenvolvimento do estado a curto, médio e longo prazos. $\mathrm{O}$ texto do Plano Mineiro de Desenvolvimento Integrado de 2004-07 expressa a importância dada à função planejamento estratégico no governo:

O Plano Mineiro de Desenvolvimento Integrado (PMDI) é, na sua essência, um plano estratégico indicativo para o estado de Minas Gerais. Nesse sentido, consolida um conjunto de grandes escolhas que orientarão a construção do futuro de Minas Gerais num horizonte de longo prazo (2020) e sob condições de incertezas. Desse modo, o PMDI representa uma resposta consistente a três grandes questões: 1 . onde estamos? 2. aonde pretendemos estar? 3. como "chegar lá"? 
Segundo Kaplan e Norton (1997), um sistema de medição de desempenho organizacional bem construído é capaz de alinhar toda a organização em torno da estratégia organizacional. Seguindo as tendências da administração pública na adoção de novas práticas de medição de desempenho organizacional (SMD) e de gestão por resultados (Trosa, 2001; Paula, 2005), o governo de Minas Gerais procurou alinhar-se em torno de sua estratégia político-administrativa e adotar o foco nos resultados como uma diretriz, no intuito de garantir a execução dos projetos prioritários e maior coerência no processo de tomada de decisões. Assim, para garantir que as estratégias do governo fossem efetivamente implementadas, a partir do PMDI foi elaborada uma carteira de 30 projetos estruturadores, denominada Gestão Estratégica dos Recursos e Ações do Estado (Geraes).

Além de viabilizar o gerenciamento mais intenso sobre a Geraes, o planejamento estratégico também deveria envolver o contexto político e, portanto, a participação dos deputados estaduais, uma vez que a execução dos projetos estruturadores dependeria da definição de metas e da aprovação dos orçamentos constantes do PPAG e das LOAs, respectivamente. A figura 1, apresentada no PMDI 2004-07, explicita como foi elaborado o planejamento estratégico do governo.

\section{Figura 1}

\section{Elaboração do Plano Mineiro de Desenvolvimento Integrado}

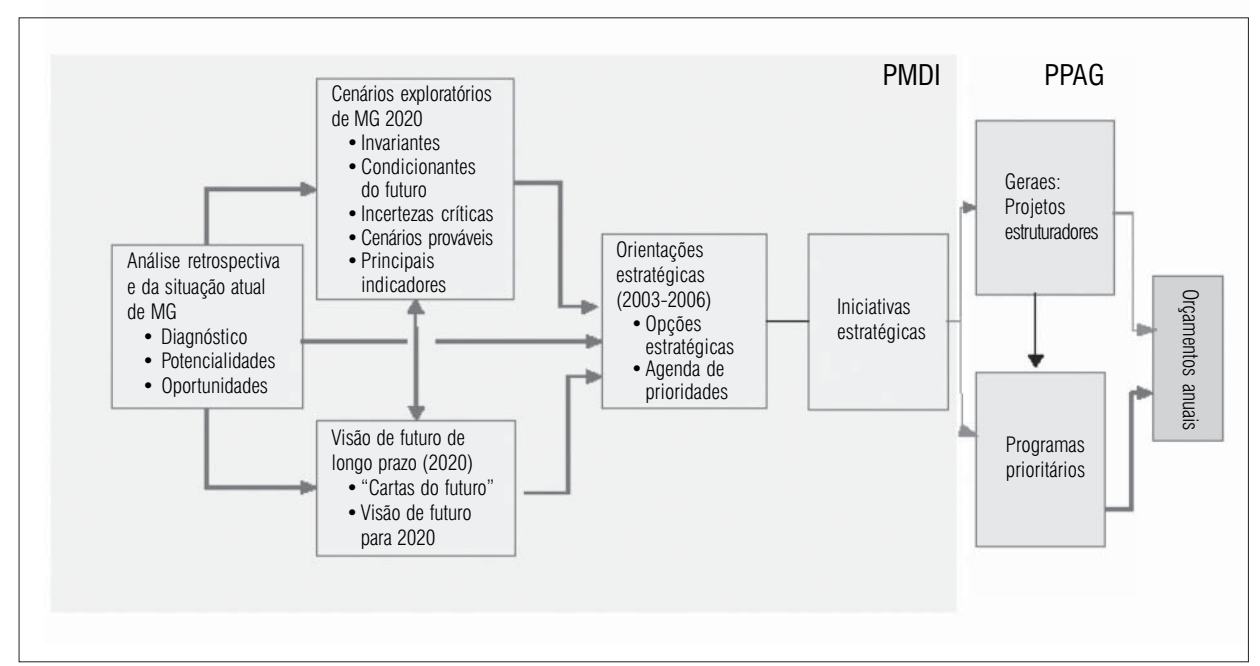

Fonte: PMDI 2004-07.

Ora, uma vez que o Executivo propôs uma estratégia de governo que relacionava seu planejamento estratégico ao ciclo orçamentário, torna-se de fundamental importância analisar como o governo procurou aproximar-se e 
relacionar-se com o Legislativo, uma vez que o ciclo orçamentário é submetido à aprovação da Assembléia Legislativa de Minas Gerais.

\section{A participação da Assembléia Legislativa e dos cidadãos no processo de planejamento do estado de Minas Gerais}

Entrelaçar a questão orçamentária ao planejamento do governo do estado, numa tentativa completa de implementação dos projetos estruturadores, envolvia, também, variáveis políticas. No Brasil, o ciclo orçamentário é composto por leis e, portanto, depende da aprovação dos parlamentares em relação ao que o Executivo propôs. Vale, assim, lembrar que o Legislativo é um corpo político composto por legisladores de partidos e correntes políticas e ideológicas diversas e, em muitos casos, distintas das do governo.

Segundo Girishankar (2001), em um processo de reforma institucional, as instituições que mais importam são as que ajudam os sistemas e estruturas estatais a transformar inputs em outputs e outcomes, facilitando a atuação do governo e o controle dos cidadãos. A gestão pública por resultados caracteriza-se, também, por ser um dos instrumentos facilitadores da promoção de maior accountability e responsiveness. Segundo Kettl (1998),

\footnotetext{
As tendências favoráveis à gestão pública "testadas no mercado" baseiam-se também na possibilidade de avaliar o desempenho do aparelho de Estado. Quando se criam incentivos à eficiência, devem-se criar também meios de avaliar diferentes alternativas. Determinado programa funciona bem? Há melhores? A resposta a estas questões fundamentais depende basicamente de que se apossa aferir resultados e adotar o critério de avaliação para orientar as decisões de política pública. Os serviços ao consumidor, sobretudo, dependem de que se possa oferecer informação suficiente para que os cidadãos-consumidores façam escolhas inteligentes. A avaliação de desempenho, portanto, é a pedra fundamental de muitas reformas.
}

Seguindo a opção pelo planejamento estratégico, o Executivo negociou com a Assembléia Legislativa de Minas Gerais a participação dos cidadãos na consolidação do PPAG no concernente aos projetos estruturadores. A cada ano de instituição ou revisão do PPAG, a Assembléia Legislativa passou a organizar audiências públicas do PPAG para que os cidadãos pudessem fazer sugestões de emendas ao plano, bem como pudessem cobrar do governo as ações previamente comprometidas pelo Executivo. As sugestões dos cidadãos são submetidas à Comissão de Participação Popular (CPP) para que ela analise e defina pela inserção - ou não — da proposta de emenda realizada pelos cidadãos. 
Além de a CPP ser um projeto de um partido de oposição ao governo, a negociação política também dentro da Assembléia Legislativa foi responsável pelo sucesso do planejamento estratégico do governo no estado de Minas Gerais, conforme pode ser destacado em trechos da entrevista abaixo:

\begin{abstract}
Quando discutimos a formatação da Comissão de Participação Popular houve uma intencionalidade política de fortalecer o papel da participação no sistema de leis orçamentárias. (...) Estipulamos prazos específicos para este tipo de atuação. Uma das coisas mais importantes que o Poder Legislativo faz é exatamente analisar as leis orçamentárias e fiscalizar a execução destas leis. Com relação à construção do 1 o Plano Plurianual [com participação popular], houve uma definição política, porque 2003 era o ano em que o governo enviaria o Plano Plurianual. Foi decisão política da CPP priorizar a discussão do Plano Plurianual de Ação Governamental, pela sua importância na construção de políticas públicas no estado. (...) Fizemos uma opção em construir com o governo do estado essa parceria, porque: primeiro, quem formula o PPAG é o governo do estado; segundo, a disponibilização de informações depende muito do governo do estado; terceiro, a base do governo, sendo amplamente majoritária na Assembléia, a possibilidade de êxito desta participação dependeria totalmente desta parceria com o governo. (...) Buscamos essa parceria por uma leitura política de eficácia. (...) O governo do estado também valorizou o instrumento do PPAG na sua estratégia de governo. (...) Os projetos estruturadores são a espinha dorsal do rumo que o governo quer imprimir no estado. A decisão foi, então, compartilhada com o estado. Acho que o governo do estado também se interessou [pela formatação CPP — PPAG] para divulgar seus projetos estruturadores e fortalecer o instrumento de planejamento. Tanto é que a análise de Lei Orçamentária hoje na Assembléia é rigorosamente vinculada ao planejamento, como ainda não havia acontecido. ${ }^{4}$
\end{abstract}

A vocalização de preferências dos cidadãos também foi viabilizada pela implementação do planejamento estratégico com foco nos resultados entrelaçado ao orçamento. Durante o processo de discussão do PPAG, diversas ações do Plano Plurianual foram alteradas e uma proposta popular deu origem ao 31ํำ projeto estruturador, denominado "Inclusão Social das Famílias Vulnerabilizadas". Esse projeto, assim como os demais 30 projetos estruturadores, recebeu intensivo acompanhamento e apoio gerencial, tendo sido o de maior

\footnotetext{
${ }^{4}$ Entrevista com o deputado André Quintão, do Partido dos Trabalhadores, realizada em 21 de outubro de 2005. Destaques da autora.
} 
execução orçamentária até a primeira revisão do PPAG, quando novas metas foram definidas.

No concernente às negociações das audiências públicas do PPAG, é relevante notar que o governo também acordou com a Assembléia Legislativa de Minas Gerais a idéia de cotas orçamentárias para incidência das emendas dos deputados estaduais. Por meio destas "cotas orçamentárias", cada deputado poderia apresentar emendas orçamentárias até um determinado limite financeiro. Esse fato, certamente, também favoreceu a coordenação entre participação e representação no arranjo das audiências públicas do PPAG em Minas Gerais: "Agora, aqui na Assembléia, o parlamentar (...) tem uma parcela que ele apresenta emendas ao orçamento - $\mathrm{R} \$ 600$ mil e está havendo um movimento para aumentar". ${ }^{5}$

Além do envolvimento direto dos parlamentares no processo de participação dos cidadãos no ciclo orçamentário, a definição de um montante individual por emenda para cada parlamentar reduziu ainda mais qualquer possibilidade de competição em torno da questão da participação popular nos projetos estruturadores.

A participação cidadã no ciclo orçamentário representou tanto uma oportunidade para o aprofundamento da accountability vertical quanto da accountability horizontal. Ao passo em que os cidadãos ganharam espaço para vocalizar suas preferências e ampliar o controle sobre seus representantes tanto no Legislativo quanto no Executivo - os legisladores também tiveram a possibilidade de controlar o Executivo no concernente ao resultado das políticas públicas, uma vez que a gestão pública por resultados foi, complementarmente à administração estratégica, adotada como diretriz de governo.

\section{A gestão pública por resultados como componente do planejamento estratégico em Minas Gerais}

No Brasil, assim como na América Latina, a avaliação de resultados adquiriu especial importância quando instituições como o Banco Mundial e o Banco Interamericano de Desenvolvimento (BID) passaram a fomentá-la na implementação de reformas no serviço público. Segundo Santos e Cardoso (2001),

A capacidade de avaliação pode desempenhar um papel decisivo em quatro áreas principais na gestão pública:

a) No diagnóstico inicial: a partir do cenário em que se encontra, definir as diretrizes para a formulação do tipo de política pública necessário;

\footnotetext{
${ }^{5}$ Entrevista com deputado estadual André Quintão, realizada em 21 de outubro de 2005.
} 
b) No processo decisório: apresentar alternativas de ação, avaliando custos e benefícios das políticas públicas adotadas, ajudando a identificar o que funciona e o que não funciona;

c) Durante a implementação: o monitoramento dos resultados obtidos ao longo do processo permite que o gestor "pilote" a política, efetuando os ajustes que se façam necessários, devido a mudanças no cenário;

d) Ao término da política, avaliam-se os resultados obtidos, em relação ao que se esperava inicialmente.

A gestão pública por resultados foi, assim, desenvolvida como uma estratégia que tem início no momento do planejamento estratégico e vai até o processo de feedback das políticas públicas, podendo ser considerada uma prática de boa governança e desenvolvimento institucional, respeitando princípios da distribuição eficiente de recursos públicos e accountability.

Em Minas Gerais, seguindo o arcabouço institucional da reforma administrativa do governo federal de 1995, a gestão pública por resultados foi estruturada por meio de procedimentos de contratualização em um instrumento de avaliação de desempenho chamado de acordo de resultados. Por meio do acordo de resultados o governo de Minas Gerais, mais especificamente centralizado na Secretaria de Estado de Planejamento e Gestão, passou a garantir que as demais secretarias de estado estariam buscando os resultados para o desenvolvimento do estado.

Alcançar uma boa prática de gestão pública por resultados não implica somente a implementação de mecanismos de avaliação institucional. A gestão pública por resultados é viabilizada por diversos mecanismos gerenciais, começando pelo planejamento estratégico das ações governamentais - sejam elas organizadas em projetos ou programas; ampliação da flexibilidade gerencial; desenvolvimento de indicadores de desempenho; e, por fim, a avaliação de desempenho, que além da medição das metas estabelecidas, fornece subsídios para retroalimentação de informações para o desenvolvimento de futuras metas gerenciais.

Evaluar la gestión en el contexto de la función pública implica desarrollar sistemas que ponderen adecuadamente los elementos cualitativos de la gestión, capaces de asimilar la multiplicidad de objetivos y la heterogeindad de las acciones que realizan las instituciones del Estado. (...) Para evaluar adecuadamente la gestión de un Servicio Público es necesario, previamente, definir su misión, formular los objetivos que orientan a corto, mediano y longo plazo su accionar, y estabelecer metas de productividad y de gestión. (...) La medición de indicadores de gestión, que en estricta lógica tedría que iniciarse por el proceso integral de Planificación Estratégica, debe involucrar en forma 
participativa a todos los funcionarios implicados en la producción de un servicio o función, por lo que su desarrollo e implementación deberían beneficiar tanto a sus productores como a sus destinatarios. (...) Además de las definiciones estratégicas, la medición de indicadores de gestión está condicionada por la capacidad de la institución de generar la información necesaria y de elaborar los indicadores con niveles adecuados de calidad, certeza y confiabilidad.

(Chile, 1996a)

A importância da gestão pública por resultados reside na importante distinção entre produtos e resultados, ou seja, entre outcomes e outputs. Os órgãos e entidades públicas utilizam insumos financeiros, humanos e materiais para a produção de bens e serviços (produtos), destinados à consecução dos objetivos de políticas públicas (resultados). Enquanto os produtos fornecem uma visão limitada do valor público que as políticas públicas agregam, já que a medição de produtos é um processo contínuo que agrega valor às organizações, os resultados apresentam conseqüências também para o ambiente externo.

Os projetos e programas de governo devem estar em consonância com o planejamento estratégico, bem como com os objetivos de governo, para que eles não venham a perder sua prioridade em detrimento de outras ações integradas ao planejamento estratégico, ou mesmo pelo fato de, apesar de gerar produtos satisfatórios, não gerar resultados eficientes. A figura 2 mostra o relacionamento interno de inputs, outputs e outcomes.

Figura 2

Transformando inputs em outputs

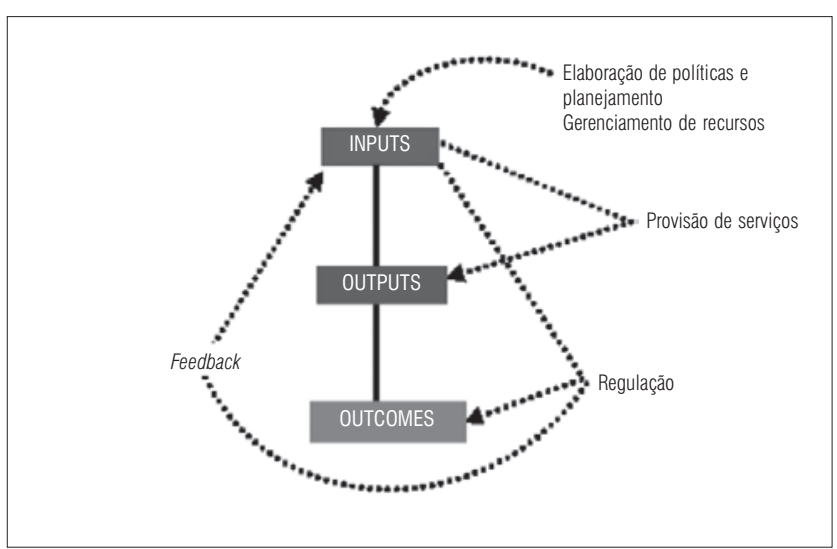

Fonte: Lawson (apud Girishankar, 2001). 
O planejamento estratégico de recursos da política pública e a seleção de políticas prioritárias servem de inputs para o processo de produção de resultados das políticas. Esse processo de transformação de inputs em outputs é realizado a partir da formulação da política pública e da alocação dos recursos administrativos nas ações que levarão aos resultados pretendidos pela política pública. Os outcomes envolvem a implementação de instituições que governam as relações entre setores da administração pública, tais como maior autonomia e flexibilização gerencial se figura como parte das instituições. Dado o foco no cumprimento de ações definidas, é necessária maior vinculação entre a alta direção e suas "unidades" operativas, para que sejam definidos as responsabilidades e compromissos mutuamente assumidos. Com o objetivo de fortalecer esse vínculo, acordos que estipulam os resultados a serem alcançados são, geralmente, articulados entre as duas partes. Nesse tipo de acordo, as unidades operativas se comprometem a cumprir com as metas previamente estabelecidas, enquanto a alta direção fornece incentivos que favorecem o alcance das metas.

Uma vez criadas as instituições que viabilizarão a prática da gestão pública por resultados, o monitoramento e a avaliação das políticas ganham importância vital para a continuidade da gestão pública por resultados. São esses dois procedimentos que permitem a revisão e o redesenho constantes das peças necessárias para incrementar o resultado das políticas públicas. Kristensen (apud Ruffner, 2002) afirma que "Outcomes reflect the intended and unintended results from government actions and provide the rationale for government interventions". O monitoramento e a avaliação se dão por meio dos indicadores de desempenho traçados para cada política pública. Dessa forma, é preciso que, além das definições estratégicas, os órgãos e entidades da administração pública sejam capazes de fornecer as informações necessárias para a elaboração de indicadores de desempenho com "níveis adequados de qualidade, certeza e confiabilidade" (Chile, 1996a, 1996b). Esses indicadores garantem o monitoramento da performance das políticas públicas, de maneira a eliminar procedimentos ineficientes e ineficazes entre os outcomes e os outputs. A internalização dessas experiências conduz a ganhos de produtividade na prestação de serviços públicos em momentos futuros, além de viabilizar maior entendimento das políticas governamentais, por parte dos cidadãos. Segundo o Banco Mundial (apud Santos e Cardoso, 2001),

No public sector can afford to overlook the importance of clearly defining its objectives and priorities, assessing performance against well-defined benchmarks, and changing the bureaucratic culture into one that stresses client service and achievement of results (...) We all have a responsibility to make sure this function is nurtured and supported (...). 
Nesse sentido, o acordo de resultados em Minas Gerais prevê maior autonomia aos órgãos e entidades que pactuarem por meio desse instrumento de gestão pública por resultados. Ao mesmo tempo em que o proponente do acordo de resultados - órgãos ou entidades - deve demonstrar seu alinhamento estratégico com relação ao governo, ele recebe incentivos para definir modelos de gestão - o que envolve processos, estruturas, pessoas, informação que viabilizem a promoção dos resultados pactuados. De forma a garantir o envolvimento tanto das secretarias de estado quanto de seus servidores, foram oferecidos incentivos interligados aos dois. Aos servidores dos órgãos e entidades que celebraram o acordo de resultados foram concedidos prêmios por produtividade quando conseguiam reduzir as despesas correntes concernentes a suas atividades. Aos órgãos e entidades acordantes foi viabilizada a aplicação dos recursos economizados no desenvolvimento de pessoal, modernização e racionalização dos serviços públicos prestados. Além de garantir maior flexibilidade e autonomia aos órgãos e entidades proponentes, o acordo de resultados ajuda na construção da cadeia causal da promoção dos resultados almejados, uma vez que indicadores intermediários também são mensurados.

Até o final do primeiro trimestre de 2006, já havia 18 órgãos e entidades pactuadas por meio do acordo de resultados. Além de garantir maior flexibilidade gerencial e administrativa aos órgãos e entidades pactuantes, com a expansão do número de acordo de resultados pactuados, o governo assegurou o alinhamento estratégico das diversas secretarias de estado e os resultados importantes para assegurar as metas do governo.

\section{Considerações finais}

A reforma da administração do setor público requer muito mais que o desenvolvimento de novas políticas públicas finalísticas. Reformar a administração do setor público requer modelos de gestão capazes de orientar os gestores públicos para os resultados almejados pelo governo. Nesse sentido, algumas ferramentas de gestão ganham especial relevância para as organizações públicas. Entre elas encontram-se o planejamento estratégico e a gestão pública por resultados. No governo do estado de Minas Gerais, o planejamento estratégico e a gestão pública por resultados foram desenhadas de forma interligada. Enquanto o planejamento estratégico apontava para os resultados que os órgãos e entidades mineiros deveriam perseguir, a gestão pública por resultados deveria garantir que esses resultados fossem alcançados.

Desenvolver o planejamento estratégico do estado exigiu coordenação tanto administrativa quanto política. Ao passo em que no setor privado são as próprias empresas que definem sua própria visão e, conseqüentemente, suas 
estratégias, no estado as estratégias do governo são sempre submetidas ao corpo Legislativo - classicamente definido como o locus de representação dos diversos segmentos da polis. O governo deve ser capaz não só de mostrar capacidade para realizar o que está propondo, mas também deve ser hábil para negociar com o Legislativo. Foi nesse sentido que o governo de Minas Gerais optou por desenvolver metas para o curto, médio e longo prazos. Enquanto algumas estratégias de gestão foram adotadas para o curto prazo - estratégias para incorporar o marco regulatório desenvolvido na reforma administrativa de 1995 - o planejamento e a gestão pública por resultados foram adotados para o médio e longo prazos. Assim, as metas de curto prazo - estrutura organizacional do estado, políticas de logística e patrimônio, gestão de recursos humanos e de tecnologia da informação - foram negociadas no Legislativo antes mesmo de o governo tomar posse. Para que isso fosse possível, o planejamento de médio e longo prazos deveria ser submetido não só à aprovação dos legisladores, mas também deveria permitir a vocalização de preferências dos cidadãos. Assim, enquanto o Executivo conseguia maior flexibilidade na implementação das políticas públicas, o Legislativo ganhava espaço para consolidar-se como o locus de manifestação dos cidadãos, tanto indireta quanto diretamente.

A estratégia de entrelaçar o planejamento estratégico à gestão pública por resultados garantiu ao governo que os diversos servidores envolvidos em todo o policy cicle estariam individualmente incentivados a contribuir para que o Estado saísse de um quadro de projetos de governo não-implementados e chegasse a um cenário de desenvolvimento integrado do estado, para, futuramente, alcançar um cenário econômico, político e institucional eficiente e competitivo. Conforme acreditava o governo, esse cenário futuro positivo seria alcançado caso os resultados alcançados pelos órgãos e entidades fossem condizentes com as estratégias do governo. Para tal, nada mais importante como a instituição da gestão pública por resultados com incentivos para os órgãos e entidades que se alinharem estrategicamente ao governo, por meio da instituição de um instrumento de gestão que assegure constantemente esse alinhamento, bem como estratégias políticas de negociação com o Legislativo e de fortalecimento da sociedade, tal como foi feito mediante pactuação com as Oscips.

\section{Referências bibliográficas}

ATKINSON, A.; WATERHOUSE, J. H.; WELLS, R. B. A stakeholder approach to strategic performance measurement. Sloan Management Review, v. 38, n. 3, 1997.

CHILE. Ministerio de Hacienda. Dirección de Presupuestos. Guia de indicadores. 1996a. Disponível em: <www.dipres.cl/>. 
. Ministerio de Hacienda. Dirección de Presupuestos. Série guia metodológica. 1996b. Disponível em: <www.dipres.cl/>.

GAETANI, F. Public management constitutional reforms in modern Brazil 1930-1998. 2005. Tese (Doutorado) - London School of Economics and Political Science, University of London, London.

GIRISHANKAR, N. Evaluating public sector reform: guidelines for assessing country-level impact of structural reform and capacity building in the public sector. Washington: World Bank/OED, 2001.

KAPLAN, R. S.; NORTON, D. P. A estratégia em ação: balanced scorecard. Rio de Janeiro: Campus, 1997.

KETTL, D. F. A revolução global: a reforma da administração do setor público. In: PEREIRA, L. C. B.; SPINK, P. (Orgs.). Reforma do Estado e administração pública gerencial. Rio de Janeiro: FGV, 1998.

LIJPHART, A. Modelos de democracia: desempenho e padrões de governo em 36 democracias. Rio de Janeiro: Civilização Brasileira, 2003.

LIMA JUNIOR, O. B. As reformas administrativas no Brasil: modelos, sucessos e fracassos. Revista do Serviço Público, v. 49, n. 2, abr./jun. 1998.

MARE (Ministério de Administração e Reforma do Estado). Plano Diretor da Reforma Administrativa do Aparelho do Estado. Brasília: Mare, 1995.

MINAS GERAIS. Secretaria de Estado de Planejamento e Gestão. Plano Mineiro de Desenvolvimento Integrado. Secretaria de Estado de Planejamento e Gestão, set. 2003.

Secretaria de Estado de Planejamento e Gestão. Indicadores de desempenho para o acordo de resultados. Secretaria de Estado de Planejamento e Gestão, 4. versão, ago. 2004.

. Secretaria de Estado de Planejamento e Gestão. Manual: alinhamento estratégico, revisão do PPAG, acordo de resultados. Secretaria de Estado de Planejamento e Gestão, 4. versão, set. 2004 .

OFFE, C. Problemas estruturais do Estado capitalista. Rio de Janeiro: Tempo Brasileiro, 1984.

PAULA, A. P. P. de. Por uma gestão pública. São Paulo: FGV, 2005.

PRZEWORSKI, A. Democracia e mercado: reformas políticas e econômicas na Europa Oriental e na América Latina. Rio de Janeiro: Relume-Dumará, 1994.

Estado e economia no capitalismo. Rio de Janeiro: Relume-Dumará, 1995. 
RUFFNER, M. Governing for results. In: CONGRESO INTERNACIONAL DEL CLAD SOBRE LA REFORMA DEL ESTADO Y DE LA ADMINISTRACIÓN PÚBLICA, 7., 2002, Lisboa, Proceedings...

SANTOS, L. A. dos; CARDOSO, R. L. dos S. Avaliação de desempenho da ação governamental no Brasil: problemas e perspectivas. In: CONCURSO DE ENSAYOS DEL CLAD, 2001. Caracas.

THE ECONOMIST. Japan's election. Disponível em: <www.economist.com>. Acesso em: 15 set. 2005 a.

A surprise that leaves Germany in limbo. Disponível em: <www.economist.com>. Acesso em: 19 set. 2005 b.

TROSA, S. Gestão pública por resultados: quando o Estado se compromete. Rio de Janeiro: Revan, 2001. 